\title{
PEMANFAATAN PEKARANGAN RUMAH UNTUK BERTANAM SAYURAN ORGANIK DALAM RANGKA MEWUJUDKAN KEMANDIRIAN PANGAN KELUARGA
}

\section{UTILIZATION OF HOUSEHOLDS FOR ORGANIC VEGETABLES IN ORDER TO REALIZE FAMILY FOOD INDEPENDENCE}

\author{
Fauziah Syamsi ${ }^{1}$, Dini Anggraini ${ }^{2}$ dan Ramses ${ }^{1 *}$ \\ ${ }^{1}$ Prodi Pendidikan Biologi, FKIP, Universitas Riau Kepulauan \\ ${ }^{2}$ Prodi Manajemen, Fakultas Ekonomi Universitas Riau Kepulauan \\ *ramses.firdaus@gmail.com; fauziahsyamsi@yahoo.co.id; dini3385@gmail.com
}

\begin{abstract}
Abstrak
Konsumsi sayuran setiap hari harus dilakukan karena sayuran sangat penting bagi tubuh manusia. Oleh karenanya diperlukan usaha-usaha dalam mendapatkan sayuran yang sehat dengan harga murah. Salah satu usaha yang sangat mungkin dilakukan masyarakat adalah dengan menanam sendiri di pekarangan rumah. Tujuan kegiatan pengabdian ini untuk menumbuhkembangkan minat dan motivasi masyarakat untuk dapat menanam sayuran secara mandiri di rumah sehingga dapat mengurangi pengeluaran belanja dan dapat mewujudkan kemandirian pangan keluarga, khususnya dalam pemenuhan nutrisi sayuran. Pekarangan rumah dapat dimanfaatkan untuk bertanam sayuran yang bisa dikonsumsi sehari-hari. Disamping itu, sampah rumah tangga juga bisa diolah menjadi pupuk yang dapat menunjang pertumbuhan sayuran. Dengan demikian, masyarakat dapat menghemat pengeluaran belanja karena sayuran yang dikonsumsi merupakan tanaman pekarangan sendiri. Dari kegiatan tersebut dapat disarankan supaya warga lebih antusias dalam memanfaatkan pekarangan rumahnya menjadi lahan yang menghasilkan, baik untuk konsumsi sendiri atau bahkan dapat dipasarkan.
\end{abstract}

Kata Kunci :Pemanfatan Pekarangan Rumah, Sayur Organik, Makanan

\begin{abstract}
Daily consumption of vegetables must be done because vegetables are very important for the human body. Therefore efforts are needed to get healthy vegetables at low prices. One effort that is very likely to be carried out by the community is to plant themselves in the yard of the house. The purpose of this service activity is to develop people's interest and motivation to be able to grow vegetables independently at home so that they can reduce spending and can achieve family food independence, especially in fulfilling vegetable nutrition. Home yards can be used to grow vegetables that can be consumed daily. Besides that, household waste can also be processed into fertilizers that can support vegetable growth. Thus, the community can save on expenditure because vegetables consumed are their own garden plants. From these activities, it can be suggested that citizens be more enthusiastic in utilizing their home yards to produce land, both for self-consumption or even marketable.
\end{abstract}

Keywords: Utilization of Home Yard, Organic Vegetables, Food

\section{PENDAHULUAN}

Sayur merupakan sumber makanan yang mengandung gizi lengkap dan sehat. Sayur berwarna hijau merupakan sumber karoten (provitamin A). Semakin tua warna hijaunya, maka semakin banyak kandungan karotennya. Kandungan beta karoten pada sayuran 
membantu memperlambat proses penuaan dini, mencegah resiko penyakit kanker, meningkatkan fungsi paru-paru dan menurunkan komplikasi yang berkaitan dengan diabetes. Sayuran yang berwarna hijau tua diantaranya adalah kangkung, daun singkong, daun katuk, daun papaya, genjer dan daun kelor. Di dalamnya juga terdapat vitamin yang bekerja sebagai antioksidan. Antioksidan dalam sayur dan buah bekerja dengan cara mengikat lalu menghancurkan radikal bebas dan mampu melindungi tubuh dari reaksi oksidatif yang menghasilkan racun (Padmiari dan Hadi, 2010). Konsumsi sayuran merupakan rutinitas yang baik dilakukan demi menjaga keseimbangan nutrisi bagi tubuh.Sayuran memberikan manfaat yang cukup banyak bagi tubuh. Hamidah (2015) menjelaskan bahwa sayuran memiliki manfaat bagi tubuh antara lain sebagai sumber vitamin dan serat, dan yang penting adalah menopang kehidupan manusia untuk menjaga agar tubuh tetap sehat.

Menurut Sekarindah (2008), apabila terjadi kekurangan dalam mengkonsumsi sayuran dan buah akan menyebabkan tubuh kekurangan vitamin, mineral, serat dan tidak seimbangnya asam basa tubuh, sehingga dapat mengakibatkan timbulnya berbagai penyakit. Ruwaidah (2009) juga menjelaskan kurangnya konsumsi buah dan sayur dapat mengakibatkan berbagai dampak yaitu menurunnya imunitas/kekebalan tubuh seperti mudah terkena flu, mudah mengalami stress atau depresi, tekanan darah tinggi, gangguan-pencernaan seperti sembelit, gusi berdarah, sariawan, gangguan mata, kulit keriput, arthritis, osteoporosis, jerawat, kelebihan kolesterol darah dan kanker.

Perilaku orang dewasa dalam mengkonsumsi sayur dan buah akan mendorong anakanaknya melakukan hal yang sama (Nurdianah, 2014). Selanjutnya Lyonni (2014) mengatakan media massa juga mempengaruhi pengetahuan tentang asupan sayur dan buah. Penelitian Schlenker and Long (2007) menyatakan bahwa perkembangan teknologi dan media massa memiliki peran dalam pemilihan makanan.

Untuk dapat mengonsumsi beragam sayuran setiap hari membutuhkan biaya yang cukup tinggi, khususnya di kota Batam yang memiliki harga sayuran lebih tinggi dibandingkan harga nasional. Tingginya harga sayuran di kota Batam disebabkan karena beberapa hal, diantaranya adalah 1) lahan pertanian yang kurang subur sehingga diperlukan upaya pemupukan yang lebih intensif; 2) mahalnya harga pupuk karena sebagian besar didatangkan dari luar kota Batam, 3) sebagian besar sayuran yang di pasarkan di Batam didatangkan dari kota-kota besar di sekitarnya seperti Tanjungpinang, Medan, Pekanbaru dan 
bahkan dari Johor, Malaysia. Dengan demikian, biaya yang dikeluarkan masyarakat untuk memenuhi kebutuhan pangan, termasuk sayuran di kota Batam tergolong tinggi. Tingginya harga sayuran ini mengakibatkan sebagian masyarakat mengabaikan kebutuhan sayuran dengan tidak menghadirkan menu sayuran di setiap waktu makan. Sikap ini memberikan dampak secara langsung ataupun tidak langsung baik bagi anak-anak ataupun orang dewasa yang ada pada keluarga tersebut.

Data dari KP2K Kota Batam menyebutkan selama tahun 2015 jumlah kebutuhan masyarakat akan sayuran sebanyak 49 ton sedangkan produksi hanya 25 ton. Tingginya permintaan ini tidak sebanding dengan jumlah produksi sayuran yang dihasilkan petani di Batam. Karenanya, pemerintah harus mendatangkan sayuran dari luar pulau Batam seperti, Medan, dan Pulau Sumatera, Tanjungpinang. (Batam Pos, 19 Desember 2016). Ketua Himpunan Kerukunan Tani Indonesia (HKTI) Kota Batam Gunawan Satary menilai, mahalnya harga kebutuhan pokok di Batam, khususnya sayuran, karena Batam masih tergantung pada daerah lain. Pasokan lokal belum mampu 100 persen. Hanya 40\% kebutuhan sayur dipasok oleh petani lokal Batam (Batam Pos, 12 Februari 2018.)

Mengingat pentingnya manfaat sayuran bagi tubuh manusia, maka konsumsi sayuran setiap hari harus dilakukan. Untuk itu diperlukan usaha-usaha dalam mendapatkan sayuran yang sehat dengan harga murah. Salah satu usaha yang sangat mungkin dilakukan masyarakat adalah dengan menanam sendiri di pekarangan rumah. Pada dasarnya, menanam sayuran bukanlah hal yang sulit. Namun, pengetahuan bagaimana cara bertanam sayuran yang baik di lahan sempit seperti di pekarangan rumah belum banyak diketahui. Untuk itu diperlukan sosialisasi dan pelatihan bagaimana cara bertanam sayuran di lahan terbatas.

Tujuan kegiatan pengabdian ini untuk menumbuhkembangkan minat dan motivasi masyarakat untuk dapat menanam sayuran secara mandiri di rumah sehingga dapat mengurangi pengeluaran belanja dan dapat mewujudkan kemandirian pangan keluarga, khususnya dalam pemenuhan nutrisi sayuran.

\section{METODOLOGI}

Kegiatan "Pemanfaatan Pekarangan Rumah untuk Bertanam Sayuran Organik dalam Rangka Mewujudkan Kemandirian Pangan Keluarga” ini dilaksanakan pada bulan Agustus 2018 di Kavling Bagan, RW 08 Kelurahan Tanjung Piayu Kecamatan Sungai Beduk Kota 
Batam. Bentuk kegiatan merupakan sosialisasi dan pelatihan. Penyampaian materi sosialisasi dilakukan dengan diskusi dan tanya jawab dengan warga, pada kegiatan pelatihan dilakuakan dengan penyampaian materi dan dilakukan praktek menyiapkan media tanam, pembibitan/penyemaian bibit, sampai proses penanaman dalam polibag serta pembuatan pupuk organik berbahan baku sampah.

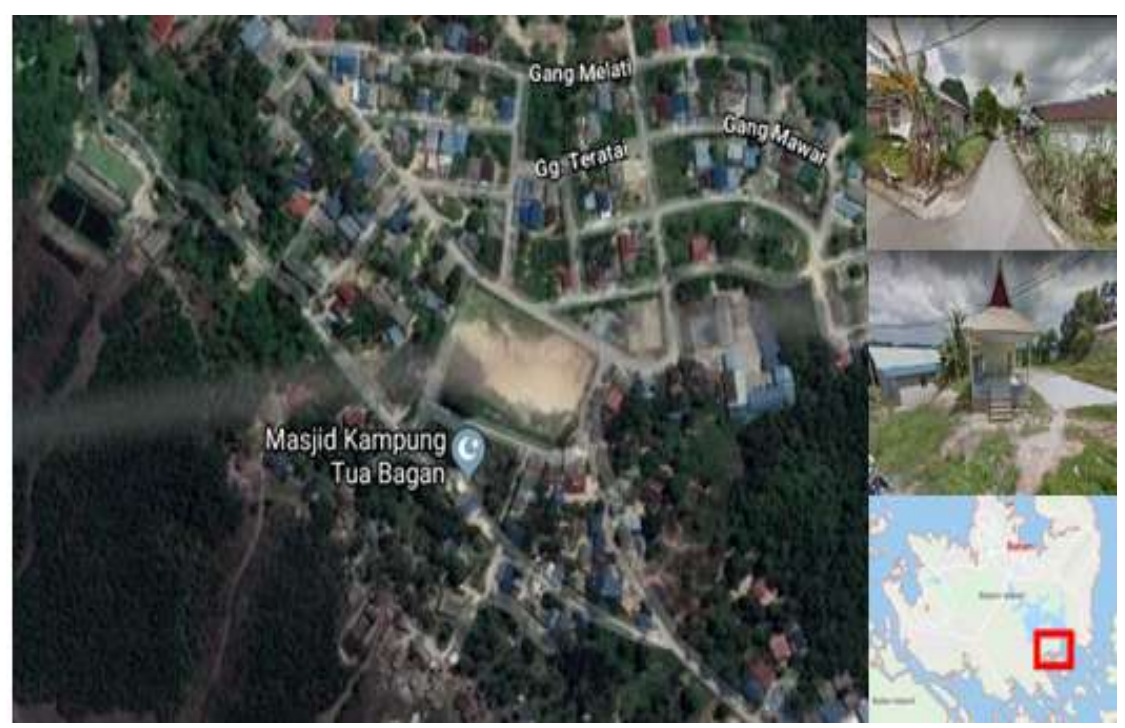

Figur 1. Lokasi kegiaatan di komunitas Kavling Bagan

\section{PEMBAHASAN}

Kegiatan "Sosialisasi dan pelatihan Pemanfaatan Pekarangan Rumah untuk Bertanam Sayuran Organik dalam Rangka Mewujudkan Kemandirian Pangan Keluarga” ini sangat disambut baik oleh warga. Hal ini ditandai dengan banyaknya warga yang hadir, khususnya ibu-ibu. Disamping itu, kegiatan ini juga dihadiri oleh Ketua RW setempat, Bapak Zakaria yang mendukung penuh pelaksanaan kegiatan demi peningkatan kapasitas warga. Kegiatan ini mendorong masyarakat agar gemar memakan sayur. Selain menyehatkan, makan sayur juga berfungsi untuk pertumbuhan, pemeliharaan dan perbaikan sel- sel tubuh serta meningkatkan kekebalan tubuh. Pentingnya bahan makanan bagi tubuh membuat seseorang harus benarbenar memperhatikan pola makan sehari- hari agar tetapsehat dan terhindar dari berbagai macam penyakit. Sakarinda, 2008.

\section{Sosialisasi}

Sosialisasi dilakukan dengan memberikan pemaparan materi yang berkaitan dengan tanaman sayuran, manfaat, bagaimana menanan sayuran yang baik, manfaat dan cara 
pembuatan pupuk organik dan bagaimana cara merawat tanaman. Materi disampaikan secara ringan dengan bahasa yang mudah dipahami oleh warga serta menampilkan gambar atau video yang mendukung materi yang dipaparkan.

Proses sosialisasi berjalan dengan lancar. Warga sangat antusias sehingga pada sesi diskusi banyak pertanyaan yang disampaikan warga yang dapat dijadikan bahan diskusi bersama. Sosialisasi memberikan pemahaman kepada warga bahwa konsumsi sayuran sangat penting bagi tubuh kita serta untuk mendapatkan sayuran secara cuma-cuma tidak sulit, yaitu dapat dengan menanam sendiri di pekarangan rumah.

Materi pada tahap sosialisasi meliputi: 1) Manfaat Mengkonsumsi Sayuran bagi Tubuh; 2) Pemanfaatan Pekarangan Rumah Sebagai Lahan Pertanian; 3) Pupuk Organik berbahan baku sampah rumah tangga.; 4) Cara merawat tanaman agar tidak mudah layu dan bertumbuh dengan baik.

\section{Pelatihan Menanam Sayur Organik}

Pada sesi ini warga dilatih untuk menanam sayuran, mulai dari menyiapkan media tanam, penanaman bibit dan perawatan tanaman. Setelah dibekali dengan beberapa materi yang mendasari kegiatan pemanfaatan pekarangan rumah sebagai lahan pertanian, masyarakat diajarkan secara langsung bagaimana cara bertanam yang baik di lahan yang terbatas. Adapun tahapan pelatihan adalah sebagai berikut:

\section{a. Persiapan media tanam}

Media tanam yang digunakan adalah tanah hitam dan pupuk kompos yang diaduk secara merata dengan perbandingan 1:1. Setelah tercampur rata, media dimasukkan ke dalam polybag sedikit demi sedikit sampai polybag penuh. Cara ini digunakan supaya tanah yang masuk tetap dalam keadaan gembur (tidak padat) sehingga akar tanaman bisa dengan mudah menembus tanah dan mendapatkan unsur hara yang dibutuhkan.

\section{b. Memasukkan bibit ke media tanam}

Bibit sayuran dimasukkan ke dalam polybag yang sudah berisi media tanam.Selanjutnya bibit ditutup dengan media tanam maksimal $2 \mathrm{~cm}$, tidak usah terlalu tebal untuk menghindari bibit gagal tumbuh.Selanjutnya dilakukan penyiraman secukupnya. Polybag yang sudah selesai ditanami diletakkan di tempat yang teduh sampai biji berkecambah dan sudah cukup kuat untuk diletakkan di bawah sinar matahari. 


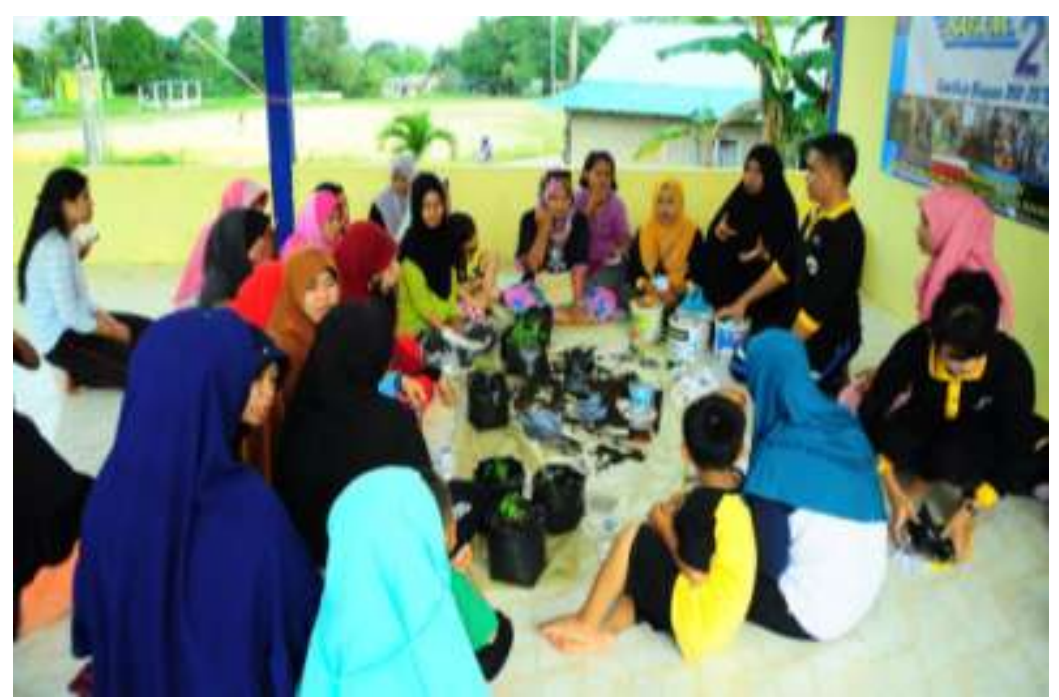

Hal. 9-15

Figur 2. Proses pelatihan penyiapan media tanam dan penanaman bibit

\section{c. Perawatan tanaman}

Setelah penanaman sayuran selesai dilakukan, peserta diajarkan bagaimana melakukan perawatan tanaman, membersihkan gulma, menggemburkan tanah secara berkala supaya udara dan unsur hara dapat masuk ke lapisan yang terdalam

\section{d. Pembuatan pupuk organic berbahan baku sampah}

Warga diajarkan bagaimana cara membuat pupuk organic dari sampah rumah tangga. Adapun langkah-langkahnya adalah sebagai berikut:

1. Siapkan sampah organik yang tidak mengandung minyak

2. Masukkan ke dalam alat penghancur (bisa menggunakan blender), tambahkan air secukupnya dan haluskan sampah

3. Bubur sampah yang sudah terbentuk dapat langsung diaplikasikan di atas media tanam.

Pelatihan pembuatan pupuk bertujuan untuk memanfaatkan sampah organik yang dihasilkan rumah tangga menjadi bahan yang bernilai guna. Dengan demikian warga tidak perlu mengeluarkan biaya untuk menyediakan pupuk. Proses pembuatan pupuk sangat mudah dan tidak memerlukan peralatan yang khusus, dengan demikian sangat mungkin dilakukan oleh warga secara mandiri. Kelemahan dari penggunaan pupuk dengan metode pembuatan seperti di atas adalah karena pembusukan sampah baru terjadi saat sudah diaplikasikan, kadang kala akan menghasilkan aroma yang kurang sedap dan mengundang lalat buah untuk 
berkunjung. Kelebihannya adalah metoda ini sangat praktis dan sangat mudah dilakukan namun tetap memberikan manfaat yang baik bagi tanaman.

\section{KESIMPULAN DAN SARAN}

Adapun kesimpulan yang diperoleh dari kegiatan ini adalah pekarangan rumah dapat dimanfaatkan untuk bertanam sayuran yang bisa dikonsumsi sehari-hari. Disamping itu, sampah rumah tangga juga bisa diolah menjadi pupuk yang dapat menunjang pertumbuhan sayuran. Dengan demikian, masyarakat dapat menghemat pengeluaran belanja karena sayuran yang dikonsumsi merupakan tanaman pekarangan sendiri. Dari kegiatan tersebut dapat disarankan supaya warga lebih antusias dalam memanfaatkan pekarangan rumahnya menjadi lahan yang menghasilkan, baik untuk konsumsi sendiri atau bahkan dapat dipasarkan.

\section{REFERENSI}

Batam Pos, 2018. 40 Persen Sayuran Dipasok Petani Lokal. 12 Februari 2018. https://batampos.co.id/2018/02/12/40-persen-sayuran-dipasok-petani-lokal/

Batam Pos. 2016 Setahun, Warga Batam Perlu 49 Ton Sayur. 19 Desember 2016. https://batampos.co.id/2016/12/19/setahun-warga-batam-perlu-49-ton-sayur/

Hamidah, S. 2015. Sayuran Dan Buah Serta Manfaatnya Bagi Kesehatan. Disampaikan Dalam Pengajian Jamaah Langar Mafaza Kotagede Yogyakarta. MAFAZA, 18 JANUARI 2015. http://staffnew.uny.ac.id/upload/130799888/penelitian/sayuran.pdf

Lyonni A. 2014. Gambaran Pengetahuan, Sikap, Ketersediaan Dan Pola Konsumsi Sayur Dan Buahremaja di Kabupaten Toraja Utara. [skripsi] Program Studi Ilmu Gizi Fakultas Kesehatan Masyarakat, Universitas Hasanuddin. Makasar.

Nurdianah A. 2014. Gambaran Pengetahuan, Sikap, Ketersediaan Dan Pola Konsumsi Sayur Dan Buah Remaja Makasar. [skripsi] Program Studi Ilmu Gizi Fakultas Kesehatan Masyarakat, Universitas Hasanuddin. Makasar.

Padmiari I.A.E, \& Hadi. H. (2010). Konsumsi Fast Food Sebagai Faktor Risisko Obesitas Pada Anak Sekolah Dasar. Fakultas Kedokteran, Universitas Gajah Mada. Yogyakarta.

Ruwaihah, A., 2009. Penyakit Akibat Lalai Mengonsumsi Buah Dan Sayur Serta Solusi Penyembuhannya. Healindonesia. 15 Mei 2009. https://healindonesia.com/ 2009/05/15/

Sakarinda, T. 2008. Terapi Jus Buah dan Sayur. Puspa Swara. Jakarta.

Schlenker E \& Long S., 2007. William's Essentials of Nutrition and Diet Therapy Ninth Edition. Canada : Mosby Elsevier pp. 288. 